Article

\title{
Betulin Suppresses Osteoclast Formation via Down-Regulating NFATc1
}

\author{
Kwang-Jin Kim ${ }^{1}$, Yongjin Lee ${ }^{1}$, Hae-Gwang Hwang ${ }^{1}$, Sang Hyun Sung ${ }^{2}$ (D), Mina Lee ${ }^{1, *}$ \\ and Young-Jin Son ${ }^{1, *}$ \\ 1 Department of Pharmacy, Sunchon National University, Jeonnam, Suncheon 57922, Korea; \\ mastiffk@naver.com (K.-J.K.); yojilee@gmail.com (Y.L.); winhhk@naver.com (H.-G.H.) \\ 2 College of Pharmacy and Research Institute of Pharmaceutical Sciences, Seoul National University, \\ Gwanak-gu, Seoul 08826, Korea; shsung@snu.ac.kr \\ * Correspondence: minalee@sunchon.ac.kr (M.L.); sony@sunchon.ac.kr (Y.-J.S.); \\ Tel.: +82-61-750-3764 (M.L.); +82-61-750-3755 (Y.-J.S.)
}

Received: 30 May 2018; Accepted: 10 June 2018; Published: 15 June 2018

\begin{abstract}
Osteoporosis is a disease characterized by osteoclast-mediated low bone mass. The modulation of osteoclasts is important for the prevention or therapeutic treatment of loss of bone mass. Osteoclasts, which are bone-resorbing multinucleated cells, are differentiated from the hematopoietic stem cell monocyte/macrophage lineage by Receptor activator of nuclear factor kappa-B ligand (RANKL) expressed from osteoblasts and stromal cells. RANKL signaling ultimately activates nuclear factor of activated T Cells 1 (NFATc1), which is a master transcription factor in osteoclastogenesis. Betulin, a lupine type pentacyclic triterpenoid, was isolated from the bark of Betula platyphylla. Betulin inhibited RANKL-mediated osteoclast differentiation by downregulating NFATc1. Betulin may serve as a useful structural scaffold in the therapeutic agent development to prevention/treatment the osteoclast-mediated bone disorder.
\end{abstract}

Keywords: bone; osteoporosis; osteoclast; RANKL; NFATc1; betulin; natural product; Betula platyphylla

\section{Introduction}

It is important to maintain the homeostasis of bone mass through the balance between the activities of osteoclasts and osteoblasts. The breaking of this homeostasis will lead to bone diseases, such as osteoporosis, rheumatoid arthritis, and multiple myeloma-related forms of bone loss [1,2]. Osteoclasts, which are bone resorbing cells, differentiate into tartrate-resistant acid phosphatase (TRAP)-positive cells, and fuse to multinucleated cells from a monocyte-macrophage lineage of hematopoietic stem cells; this process is important in bone remodeling [3,4]. Osteoclasts attach to a bone surface and secrete various types of acids and lytic enzymes, such as protons, TRAP, and cathepsin $\mathrm{K}$ for bone resorption $[5,6]$.

Osteoclastogenesis is induced by receptor activator of nuclear factor kappa-B ligand (RANKL), also known as TNF Superfamily Member 11 (TNFSF11), osteoclast differentiation factor (ODF), and TNF-related activation-induced cytokine (TRANCE), in the presence of the macrophage colony-stimulating factor (M-CSF) [7-9]. RANKL, expressed by osteoblasts/stromal cells, belongs to the tumor necrosis factor (TNF) superfamily and binds to the RANK on the surface of osteoclast precursors [10]. In particular, the RANKL-RANK signaling pathway plays an important role in osteoclast differentiation through the expression of the NFATc1, which modulates osteoclast-specific genes, such as TRAP, dendritic cell-specific transmembrane protein (DC-STAMP), calcitonin receptor, osteoclast-associated receptor (OSCAR), and cathepsin K [11-14]. 
Historically, natural products are important resources in drug discovery and have been developed for a variety of medicines, such as immunosuppressive agents, anticancer agents, and enzyme inhibitors $[15,16]$. There have been recent efforts to find drugs from natural products that prevent and treat bone diseases while minimizing adverse side effects $[17,18]$. Recently, we isolated betulin from the inner bark of Betula platyphylla with chloroform, butanol, and water. It is a lupane type pentacyclic triterpenoid, commonly isolated from the bark of yellow and white birch trees [19], and has pharmacological properties, such as anti-tumor activity, anti-inflammatory activity, anti-viral activity, and antibacterial activity [20,21]. Also, Betulin can be derived from Betulinic acid, which has been reported to suppress osteoclast differentiation and bone resorption. However, the effect of Betulin has not yet been reported $[22,23]$. Therefore, we investigated the effects of betulin on osteoclastogenesis and analyzed its molecular mechanisms in this report.

\section{Materials and Methods}

\subsection{Plant Material}

B. platyphylla inner bark was provided by SK E\&C (Chungju, Korea) and collected in the afforested land of SK E\&C, which has more than 450,000 B. platyphylla in 167.6 ha of forested area in Chungju, Korea. A voucher specimen (SNU-797) has been deposited in the herbarium of the medicinal plant garden, College of Pharmacy, Seoul National University, Koyang, Korea.

\subsection{Extraction and Isolation}

Dried and pulverized B. platyphylla bark $(5.7 \mathrm{~kg}$ ) was extracted with $80 \%$ methanol $(30 \mathrm{~L}, 3 \mathrm{~h} \times 4)$ by ultrasonication at room temperature, and was concentrated in vacuo to afford a crude extract (984.4 g), which was suspended in $\mathrm{H}_{2} \mathrm{O}$ and partitioned in $\mathrm{CHCl}_{3}(205.3 \mathrm{~g}), n$-butanol (577.5 g), and $\mathrm{H}_{2} \mathrm{O}(160.5 \mathrm{~g})$ fractions. Betulin was produced by recrystallization from $n$-butanol and $\mathrm{H}_{2} \mathrm{O}$ fraction of B. platyphylla bark. ${ }^{1} \mathrm{H}$ - and ${ }^{13} \mathrm{C}-\mathrm{NMR}$ spectra of betulin were obtained on a JEOL 400 NMR spectrometer (400 and $100 \mathrm{MHz}$ for $1 \mathrm{H}$ and 13C, respectively; Tokyo, Japan) in CDCl3 with solvent signals as internal standards. The purity of betulin was $96 \%$ by normalization of the peak areas detected by HPLC-DAD analysis.

\subsection{Cell Cultures and Osteoclast Differentiation}

This study was carried out in strict accordance with the recommendations contained in the Standard Protocol for Animal Study of Sunchon National University. The protocol was approved by the Sunchon National University Institutional Animal Care and Use Committee (SCNU IACUC; Permit No. SCNU IACUC 2016-06). All efforts were made to minimize suffering.

All cells were cultured in a $37{ }^{\circ} \mathrm{C}$ and $5 \% \mathrm{CO}_{2}$ incubator, and the medium was changed every 3 days. Bone marrow-derived macrophages (BMMs) were obtained from unfractionated bone marrow cells (BMCs) as follows: BMCs were isolated from the tibia and femur of 5-week-old male ICR mice $(n=2$ : Damool Science, KR) by flushing $\alpha$-minimum essential medium ( $\alpha$-MEM; Invitrogen Life Technologies, Carlsbad, CA, USA) supplemented with $100 \mathrm{U} / \mathrm{mL}$ penicillin/streptomycin (Invitrogen, Carlsbad, CA, USA). Cells were incubated on a petri dish in $\alpha$-MEM supplemented with $10 \%$ fetal bovine serum (FBS; Invitrogen Life Technologies, Carlsbad, CA, USA) and $100 \mathrm{U} / \mathrm{mL}$ penicillin/streptomycin $(10 \% \alpha$-MEM) with $30 \mathrm{ng} / \mathrm{mL}$ of mouse recombinant macrophage colony-stimulating factor (M-CSF; PEPROTECH, Rocky Hill, NJ, USA). After 3 days, cells attached to Petri dishes were obtained as BMMs. BMMs were plated at a density of $1 \times 10^{4}$ cells/well in a 96-well tissue culture plate in $10 \% \alpha$-MEM, and cultured with $10 \mathrm{ng} / \mathrm{mL}$ of mouse recombinant RANKL (R\&D Systems, Minneapolis, MN, USA) and $30 \mathrm{ng} / \mathrm{mL}$ M-CSF for 4 days in the presence or absence of samples. 


\subsection{Cytotoxicity Assay}

BMMs were plated in a 96-well tissue culture plate in triplicate at a density of $1 \times 10^{4}$ cells/well in 10\% $\alpha$-MEM, and cultured with $30 \mathrm{ng} / \mathrm{mL}$ M-CSF and the samples for 3 days. Cell viability was evaluated by using a CCK-8 kit (Dojindo Molecular Technologies, Kumamoto, Japan) according to the manufacturer's protocol.

\subsection{Tartrate-Resistant Acid Phosphatase (TRAP) Staining and Activity Assay}

Cultured adherent cells were fixed with 3.7\% formalin in PBS for $5 \mathrm{~min}$, permeabilized with $0.1 \%$ Triton X-100 for $10 \mathrm{~min}$, and incubated for $10 \mathrm{~min}$ with a TRAP-staining solution (Sigma-Aldrich, St. Louis, MO, USA). TRAP positive-multinucleated cells (TRAP ${ }^{+}-\mathrm{MNCs}$ ) containing three or more nuclei were counted as mature osteoclasts. Then, we added $100 \mu \mathrm{L} /$ well of TRAP buffer $(100 \mathrm{mM}$ sodium citrate, $50 \mathrm{mM}$ sodium tartrate, $1 \mathrm{mg} / \mathrm{mL}$ p-nitrophenyl, $\mathrm{pH}$ 5.0) to the 96-well plate and incubated at $37^{\circ} \mathrm{C}$ for $1 \mathrm{~h}$. The reaction mixture was transferred to a new 96-well plate containing $90 \mu \mathrm{L}$ of $0.1 \mathrm{~N} \mathrm{NaOH}$, and the absorbance at $410 \mathrm{~nm}$ was measured.

\subsection{Real-Time PCR}

BMMs were plated at $3.5 \times 10^{4}$ cells /well in a six-well tissue culture plate, and cultured with $10 \mathrm{ng} / \mathrm{mL}$ of RANKL and $30 \mathrm{ng} / \mathrm{mL}$ M-CSF for $0,1,2$, and 3 days in the presence or absence of betulin. Real-time PCR was performed as described previously [24]. Primers for real-time PCR were designed (Table 1) by using the Primer3 design program [25]. Total RNAs were isolated with a TRIzol reagent (Invitrogen, Carlsbad, CA, USA), and $1 \mu \mathrm{g}$ of RNAs were reverse-transcribed with the M-MLV cDNA Synthesis kit (Enzynomics, Daejeon, Korea) according to the manufacturer's protocol. Quantitative PCR was accomplished using TOPreal qPCR 2× PreMIX (Enzynomics, Daejeon, Korea) and Real-Time PCR detection system (Bio-Rad, Hercules, CA, USA). All tests were run in triplicate, and glyceraldehyde-3-phosphate dehydrogenase (GAPDH) was used as an internal standard, and data were analyzed by the $2^{-\Delta \Delta C T}$ method [26].

Table 1. Primer sequences used in this study.

\begin{tabular}{|c|c|c|}
\hline \multirow{2}{*}{ Gene of Interest } & \multicolumn{2}{|c|}{ Primer Sequence $\left(5^{\prime} \rightarrow 3^{\prime}\right)$} \\
\hline & Sense & Anti-Sense \\
\hline NFATc1 & GATGACTTTGCCAGTCAGCA & ACATAGCCCACACCGTTCTC \\
\hline GAPDH & AACTTTGGCATTGTGGAAGG & ACACATTGGGGGTAGGAACA \\
\hline Cathepsin K & GATGACTTTGCCAGTCAGCA & ACATAGCCCACACCGTTCTC \\
\hline DC-STAMP & CCAAGGAGTCGTCCATGATT & GGCTGCTTTGATCGTTTCTC \\
\hline TRAP & GATGACTTTGCCAGTCAGCA & ACATAGCCCACACCGTTCTC \\
\hline
\end{tabular}

\subsection{Western Blot Analysis}

Western blotting was performed as described previously [27]. Cells were washed with phosphate-buffer saline (PBS) and homogenized in lysis buffer (50 mM Tris- $\mathrm{HCl}, 150 \mathrm{mM} \mathrm{NaCl}$, $5 \mathrm{mM}$ EDTA, 1\% Triton X-100, $1 \mathrm{mM}$ sodium fluoride, $1 \mathrm{mM}$ sodium vanadate, and 1\% deoxycholate) supplemented with $1 \mathrm{mM}$ phenylmethylsulfonyl fluoride (PMSF; Bio Basic, Amherst, NY, USA). The protein concentration was determined by the DC Protein Assay (Bio-Rad, Hercules, Hercules, CA, USA). Protein extracts were subjected to $10 \%$ sodium dodecyl sulfate-polyacrylamide gel electrophoresis (SDS-PAGE) (20 $\mu \mathrm{g}$ per lane) and transferred to a polyvinylidene difluoride (PVDF) membrane (Amersham Biosciences, Piscataway, NJ, USA). After blocking with 5\% skim milk, the membranes were incubated overnight at $4{ }^{\circ} \mathrm{C}$ with primary antibodies. NFATc1 and actin antibodies were from Santa Cruz Biotechnology (Paso Robles, CA, USA). Antibodies against p38, p-p38, c-Jun N-terminal kinase (JNK), p-JNK, extracellular signal-regulated kinase (ERK), and p-ERK were obtained from Cell Signaling Technology (Danvers, MA, USA). After washing, the membranes 
were incubated with horseradish peroxidase (HRP)-conjugated secondary antibody (Santa Cruz Biotechnology, Paso Robles, CA, USA) for $2 \mathrm{~h}$ at room temperature. The antibody blots were treated with Super-Signal West Pico/Femto Chemiluminescent Substrate (Pierce Chemical, Rockford, IL, USA) and developed by using MicroChemi 4.2 (DNR Bio-imaging System, Neve Yamin, Israel).

\subsection{Bone Pit Formation Assay}

BMMs were plated on an Osteo Assay Plate (24 well plate) at a density of $3 \times 10^{5}$ cells/well and stimulated with $10 \mathrm{ng} / \mathrm{mL}$ RANKL and $30 \mathrm{ng} / \mathrm{mL} \mathrm{M}-\mathrm{CSF}$ in the presence of betulin (the indicated concentrations). After 4 days, the cells were removed completely, then the resorption area was observed under a light microscope (magnification, $\times$ 50; Leica Microsystems, Wetzlar, Germany), and after that, measured by ImageJ software (NIH, Bethesda, MD, USA). For each sample, three fields of vision were examined.

\subsection{Statistical Analysis}

All quantitative data are presented as the mean \pm standard deviation of three replicate experiments. Statistical differences were analyzed by applying Student's $t$-test. Probability $(p)$ values less than 0.05 were considered significant $\left(p\right.$ values ${ }^{*}<0.05{ }^{* *}<0.01$, and $\left.{ }^{* * *}<0.001\right)$.

\section{Results}

\subsection{Betulin Was Isolated from B. platyphylla Barks}

In the search for anti-osteoclastogenic natural products, we found that methanolic extract of B. platyphylla inner bark displayed a concentration-dependent suppression of the differentiation of BMMs into osteoclasts at the concentrations ranging from $1 \mu \mathrm{g} / \mathrm{mL}$ to $10 \mu \mathrm{g} / \mathrm{mL}$ (Figure 1). Dried and pulverized B. platyphylla bark was extracted with $80 \%$ methanol by using an ultrasonic apparatus. The $80 \%$ methanolic extract of $B$. platyphylla bark was suspended in $\mathrm{H}_{2} \mathrm{O}$ and successively fractioned into $\mathrm{CHCl}_{3}, n$-butanol, and $\mathrm{H}_{2} \mathrm{O}$ fractions. The compound, obtained as a major constituent by recrystallization from $n$-butanol and $\mathrm{H}_{2} \mathrm{O}$ fraction, was isolated as whitish needles. The molecular formula was determined to be $\mathrm{C}_{30} \mathrm{H}_{50} \mathrm{O}_{2}$ from the negative fast atom bombardment-Mass Spectrometry (FAB-MS) at $m / z=425\left[\mathrm{M}-\mathrm{H}_{2} \mathrm{O}+\mathrm{H}\right]^{-}$. The ${ }^{1} \mathrm{H}-\mathrm{NMR}$ spectrum in $\mathrm{CDCl}_{3}$ showed evidence for the presence of an isopropylene function [ $\delta 4.65(1 \mathrm{H}, \mathrm{br} \mathrm{s}, \mathrm{H}-29 \mathrm{~b}), 4.56(1 \mathrm{H}, \mathrm{br} \mathrm{s}, \mathrm{H}-29 \mathrm{~b}), 1.66(3 \mathrm{H}, \mathrm{s}, \mathrm{H}-30)]$, five tert- $\mathrm{CH}_{3}$ groups [ $\delta 1.05(3 \mathrm{H}, \mathrm{s}, \mathrm{H}-27), 1.03(3 \mathrm{H}, \mathrm{s}, \mathrm{H}-23), 1.02(3 \mathrm{H}, \mathrm{s}, \mathrm{H}-24), 0.99(3 \mathrm{H}, \mathrm{s}, \mathrm{H}-26)$, $0.96(3 \mathrm{H}, \mathrm{s}, \mathrm{H}-25)]$, geminal protons [ $33.77(1 \mathrm{H}, \mathrm{br} \mathrm{d}, J=11.0, \mathrm{H}-28 \mathrm{a}), 3.31(1 \mathrm{H}, \mathrm{br} \mathrm{d}, J=10.6, \mathrm{H}-28 \mathrm{~b})]$ for the aforesaid lupane type pentacyclic triterpenoid skeleton. The ${ }^{1} \mathrm{H}-\mathrm{NMR}$ spectrum at $\delta 3.16(1 \mathrm{H}$, $\mathrm{dd}, J=10.8,5.3 \mathrm{~Hz}, \mathrm{H}-3)$ and $\delta 3.77(1 \mathrm{H}, \mathrm{br} \mathrm{d}, J=11.0, \mathrm{H}-28 \mathrm{a}), 3.31(1 \mathrm{H}, \mathrm{br} \mathrm{d}, J=10.6, \mathrm{H}-28 \mathrm{~b})$ indicated the $\beta$-orientated hydroxyl group and hydroxymethane group, respectively. The ${ }^{13} \mathrm{C}$-NMR spectrum showed thirty carbon signals. On the basis of the above data, this compound was determined to be betulin [28] (Figure 2). 
A

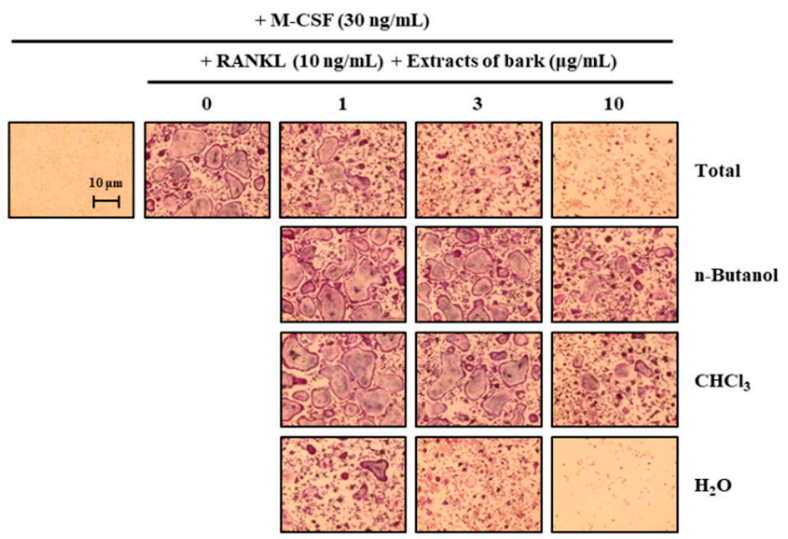

B

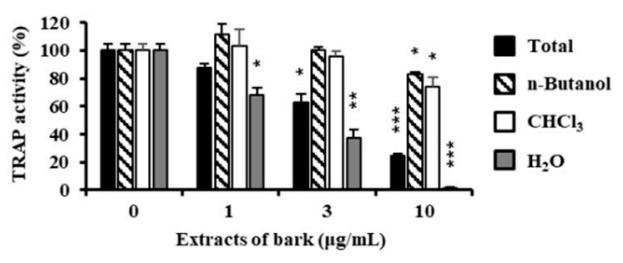

Figure 1. Effects of extracts of Betula platyphylla on the differentiation of BMMs into osteoclasts. (A) BMMs were cultured for 4 days with RANKL (10 ng/mL) and M-CSF (30 ng/mL) in the presence of the indicated concentrations of extracts. Total: $80 \%$ methanol extract of B. platyphylla barks, $n$-Butanol: n-butanol fractions of the total, $\mathrm{CHCl}_{3}: \mathrm{CHCl}_{3}$ fractions of the total, and $\mathrm{H}_{2} \mathrm{O}: \mathrm{H}_{2} \mathrm{O}$ fractions of the total; (B) TRAP activity was measured. ${ }^{*}, p<0.05 ;{ }^{* *}, p<0.01 ;{ }^{* * *}, p<0.001(n=3)$.

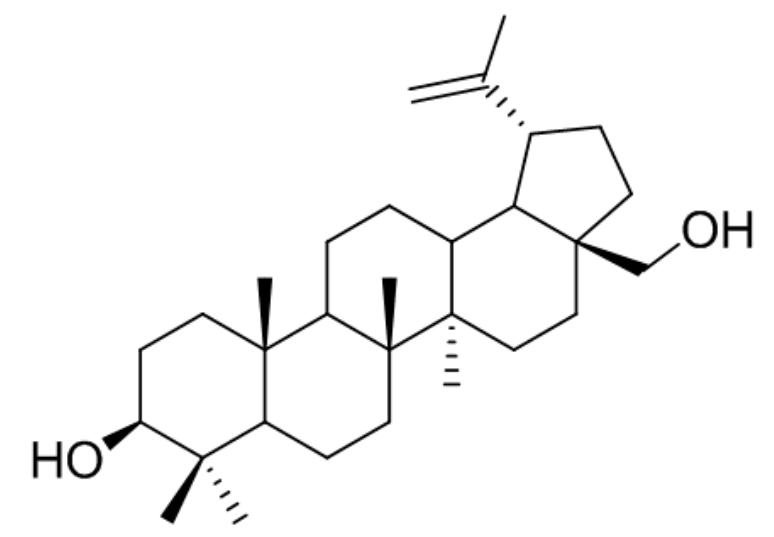

Figure 2. Chemical structure of betulin isolated from B. platyphylla.

Betulin. Whitish needles; $\mathrm{C}_{30} \mathrm{H}_{50} \mathrm{O}_{2}$; Positive FABMS $(\mathrm{m} / \mathrm{z}): 425\left[\mathrm{M}-\mathrm{H}_{2} \mathrm{O}+\mathrm{H}\right]^{+} ;{ }^{1} \mathrm{H}-\mathrm{NMR}(400 \mathrm{MHz}$, $\left.\mathrm{CDCl}_{3}\right): \delta 4.65(1 \mathrm{H}$, br s, H-29a), 4.56 (1H, br s, H-29b), $3.77(1 \mathrm{H}$, br d, $J=11.0 \mathrm{~Hz}, \mathrm{H}-28 \mathrm{~b}), 3.31(1 \mathrm{H}, \mathrm{br} \mathrm{d}$, $J=10.6 \mathrm{~Hz}, \mathrm{H}-28 \mathrm{a}), 3.16$ (1H, dd, J = 10.8, 5.3 Hz, H-3), 1.00 (3H, s, H-27), 0.95 (3H, s, H-26), 0.94 (3H, s, H-23), 0.80 (3H, s, H-25), 0.73 (3H, s, H-24); ${ }^{13} \mathrm{C}-\mathrm{NMR}\left(100 \mathrm{MHz}, \mathrm{CDCl}_{3}\right): \delta 150.5$ (C-20), 109.7 (C-29), 79.0 (C-3), 60.6 (C-28), 55.3 (C-5), 50.4 (C-9), 48.7 (C-19), 47.8 (C-17,18), 42.7 (C-14), 40.9 (C-8), 38.9 (C-1), 38.7 (C-4), 37.3 (C-10), 37.2 (C-13), 34.2 (C-7), 34.0 (C-22), 29.7 (C-21), 29.2 (C-23), 28.0 (C-2), 27.4 (C-15), 27.0 (C-12), 25.2 (C-11), 20.8 (C-30), 18.3 (C-6), 16.1 (C-25), 16.0 (C-26), 15.3 (C-24), 14.8 (C-27). 


\subsection{Betulin Inhibits the Differentiation of BMMs into Osteoclasts}

To examine the effects of betulin on the RANKL-induced osteoclast differentiation, BMMs were incubated with $30 \mathrm{ng} / \mathrm{mL}$ M-CSF and $10 \mathrm{ng} / \mathrm{mL}$ RANKL in the presence of betulin or vehicle $\left(0.1 \%\right.$ DMSO) for 4 days. Figure $3 \mathrm{~A}$ shows that RANKL significantly induced TRAP $^{+}$-osteoclast differentiation. However, the betulin above $3 \mu \mathrm{M}$ considerably inhibited the formation of $\mathrm{TRAP}^{+}$-osteoclasts. Consistent with these results, the number of $\mathrm{TRAP}^{+}$-MNCs (nuclei $\geq 3$ ) was decreased by betulin in a dose-dependent manner (Figure 3B).

A


C

Figure 3. RANKL-induced osteoclast differentiation is inhibited by betulin. (A) BMMs were cultured for 4 days with RANKL $(10 \mathrm{ng} / \mathrm{mL})$ and M-CSF $(30 \mathrm{ng} / \mathrm{mL})$ in the presence of the indicated concentrations of botulin; (B) Multinucleated cells were fixed (3.7\% formalin), permeabilized ( $0.1 \%$ Triton X-100), and stained with TRAP solution. Mature TRAP ${ }^{+}$-MNCs (nuclei $\geq 3$ ) were photographed under a light microscope. TRAP-positive MNCs (nuclear number $>3$ ) were counted. ${ }^{* *}, p<0.001(n=3)$; (C) The effect of betulin on the viability of BMMs was evaluated by the CCK-8 assay. ${ }^{* * *}, p<0.001(n=3)$.

\subsection{Betulin Had No Cytotoxic Effect}

We confirmed the toxic effect of betulin on the BMMs to determine whether betulin inhibited osteoclast differentiation through toxicity. BMMs were incubated with betulin in the presence of $30 \mathrm{ng} / \mathrm{mL} \mathrm{M}$-CSF for 3 days. Betulin showed significant cytotoxicity above $10 \mu \mathrm{M}$, whereas there was no cytotoxic effect under $3 \mu \mathrm{M}$ (Figure 3C). These results implied that betulin had the inhibitive activity against the differentiation of osteoclast without any cytotoxicity.

\subsection{Betulin Suppressed RANKL-Induced Expression of NFATc1}

The anti-osteoclastogenic activity of betulin on the expression of transcription factors and osteoclast-specific markers were confirmed by real-time PCR analysis. Betulin inhibited the mRNA expression of NFATc1 (transcription factors in osteoclastogenesis) in response to RANKL (Figure 4A). Furthermore, the mRNA levels of NFATc1-related molecules, such as DC-STAMP, cathepsin K, and TRAP, were also significantly suppressed by betulin in osteoclast differentiation (Figure 4B-D).

Additionally, to confirm this finding, we analyzed the protein expression level of NFATc1, a master regulator of osteoclast differentiation, by Western blotting. RANKL significantly increased the protein expression of NFATc1, but betulin dramatically inhibited the NFATc1 protein expression level in osteoclast differentiation (Figure 5B). This result confirmed that betulin decreased protein expression of NFATc1, and then the differentiation of osteoclast was inhibited during osteoclastogenesis. 
A

B

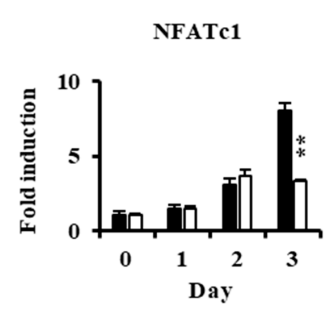

$\begin{array}{ll}\text { DC-STAMP } & \square \text { DMSO } \\ 15 & \square \text { Betulin }(3 \mu \mathrm{M})\end{array}$

C

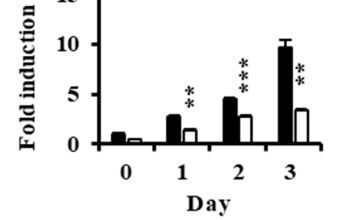

D

Cathepsin $\mathrm{K}$

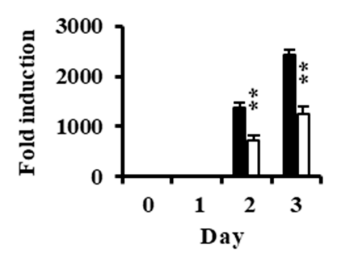

TRAP

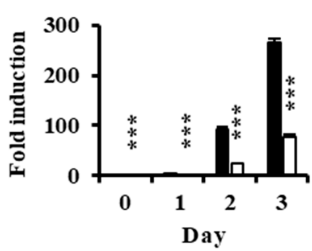

Figure 4. Effect of betulin on RANKL-induced mRNA expressions of osteoclastic-specific genes. BMMs were treated with vehicle $(0.1 \%$ DMSO) or betulin $(3 \mu \mathrm{M})$ for $1 \mathrm{~h}$, and then RANKL $(10 \mathrm{ng} / \mathrm{mL})$ and M-CSF (30 ng/mL) were treated for the indicated time periods. Total RNA was then isolated using a TRIzol reagent, and mRNA expression levels were evaluated by real-time PCR. The TRIzol reagents were used: (A) NFATc1; (B) DC-STAMP; (C) Cathepsin K; (D) TRAP. Glyceraldehyde-3-phosphate dehydrogenase (GAPDH) was used as the internal control. ${ }^{* *}, p<0.01 ;{ }^{* * *}, p<0.001(n=3)$.



Figure 5. Betulin downregulated RANKL-mediated activation of NFATc1 through inhibition of p38 phosphorylation in BMMs. The effects of betulin on RANKL-induced phosphorylation of MAP kinases and degradation of I-kB and NFATc1 were evaluated by Western blot analysis. Actin was used as an internal control. (A) BMMs were pretreated with vehicle $(0.1 \% \mathrm{DMSO})$ or betulin $(3 \mu \mathrm{M})$ for $1 \mathrm{~h}$ prior to RANKL (10 ng/mL) stimulation at the indicated time periods; (B) BMMs were treated with vehicle $(0.1 \%$ DMSO $)$ or betulin $(3 \mu \mathrm{M})$ for $1 \mathrm{~h}$, and then RANKL $(10 \mathrm{ng} / \mathrm{mL})$ and M-CSF $(30 \mathrm{ng} / \mathrm{mL})$ were treated at the indicated time periods. 


\subsection{Betulin Inhibited RANKL-Induced Activation of $p 38$}

It is well known that the activity of a mitogen-activated protein kinase (MAPK) is important for osteoclast formation $[7,10]$. We, therefore, assessed the phosphorylation of p38, JNK, and ERK after RANKL stimulation in BMMs using Western blot analysis. The results demonstrated that betulin reduced the RANKL-mediated phosphorylation of p38 and did not affect the others (Figure 5A).

\subsection{Effects of Betulin on Bone Resorptive Activity in RANKL-Induced Osteoclasts}

Finally, we examined whether osteoclast formation inhibited by betulin also affected bone resorption. Wide resorption pits were formed by osteoclasts on the bone slices, but betulin decreased the area of the bone resorption pits in a dose-dependent manner (Figure 6).

$\mathbf{A}$

Betulin $(\mu \mathrm{M})$

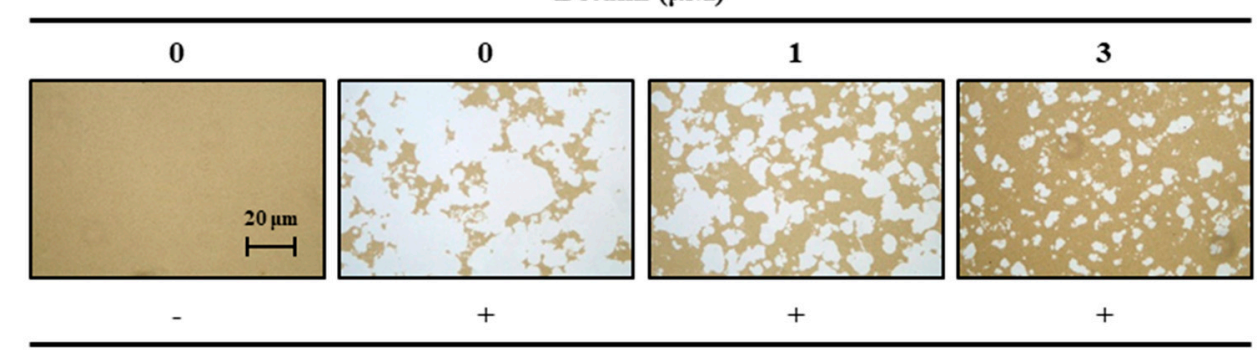

RANKL (10 ng/mL)

B

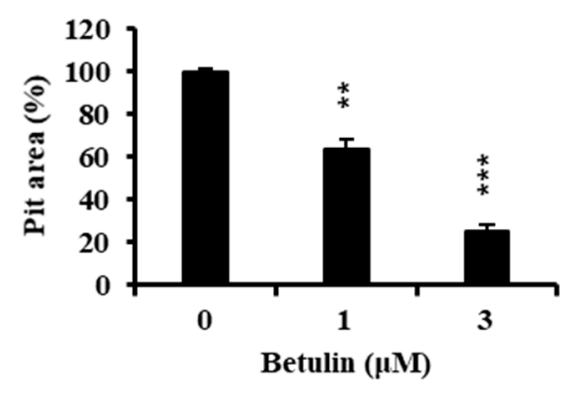

Figure 6. Betulin inhibited RANKL-induced bone resorption by osteoclasts. (A) BMMs were plated on an Osteo Assay Plate and treated with $10 \mathrm{ng} / \mathrm{mL}$ RANKL and $30 \mathrm{ng} / \mathrm{mL}$ M-CSF in the presence of different concentrations of betulin. Following 4 days of culture, the attached cells on the Osteo Assay Plate were removed and photographed under a light microscope; (B) Pit areas were quantified using the ImageJ program. ${ }^{* *}, p<0.01 ;{ }^{* * *}, p<0.001(n=3)$.

\section{Discussion}

Betulin is a naturally occurring triterpene that is often found in birch bark and is also found in the sap. Betulin is an interesting precursor with potentially important biological activity. Betulinic derivatives, such as betulinic acid, have been reported to have anti-tumor, anti-diabetic, anti-malarial, anti-inflammatory, and antifungal activity $[21,29,30]$. In addition, betulinic acid has been reported to inhibit osteoclast differentiation [22,23]. However, there is no study examining betulin in osteoclasts. Here, we examined the potential for the anti-osteoclastogenesis of betulin.

The osteoclast, which exists only in the bone, is the only cell that resorbs the bone. Therefore, it plays an important role in the sustaining of bone mass or bone strength and is a major cause of bone disease-related bone loss, including osteoporosis [31]. M-CSF and RANKL are important for osteoclast formation. M-CSF plays an important role in the proliferation and survival of macrophage progenitor cells, as well as osteoclasts, and it also stimulates RANK expression in monocytes/macrophage 
progenitor cells, allowing them to efficiently respond to RANKL [13]. The binding of RANKL and RANK in macrophages promotes the expression of transcription factor NFATc1 [32,33]. NFATc1 is a key regulator in osteoclast differentiation and upregulates TRAP, DC-STAMP, and cathepsin K, which are osteoclast differentiation markers.

Here, we investigated the effect of betulin on osteoclast differentiation. At first, before obtaining pure betulin from B. platyphylla bark, their ability of crude extracts to inhibit osteoclast differentiation was determined using an $80 \%$ methanol extract of B. platyphylla bark and its $\mathrm{CHCl}_{3}, n$-butanol, and $\mathrm{H}_{2} \mathrm{O}$ fractions. RANKL-mediated osteoclast differentiation was greatly inhibited by the total methanol extracts of B. platyphylla bark. The total methanol extract was fractionated n-butanol, chloroform, and water, where water extracts showed the greatest inhibitory effect on osteoclast differentiation. We crystallized the main component in $n$-butanol and water fractions, and then we confirmed it as betulin by NMR spectroscopic data. Betulin showed similar results to the osteoclast differentiation experiment with the extract from B. platyphylla bark, and inhibited the formation of osteoclasts at concentrations above $3 \mu \mathrm{M}$. Betulin showed cytotoxicity at concentrations above $10 \mu \mathrm{M}$. These results indicated that betulin at $3 \mu \mathrm{M}$ or less had anti-osteoclastogenic activity without cytotoxicity in BMM. It was confirmed that betulin reduced osteoclast formation. We examined the gene expression of NFATc1, the most important factor in osteoclastogenesis. The mRNA expression level of NFATc1 was inhibited by betulin, and the mRNA expression level of the specific gene in osteoclast differentiation, such as DC-STAMP, cathepsin K, and TRAP, was also significantly decreased by betulin. In addition, we investigated the effect of betulin on the MAPK signaling pathways because activation of the MAPK signaling pathways is important for RANKL-mediated osteoclast differentiation [10]. Betulin inhibited the activation of p38 by RANKL, but did not affect the activity of JNK and ERK. In addition, the protein expression level of NFATc1 was also reduced by betulin, such as gene expression levels. These results suggest that betulin inhibits osteoclastogenesis by decreasing the expression of NFATc1, including inhibition of p38 signaling in RANKL-mediated osteoclast differentiation. Furthermore, we confirmed that bone resorption was inhibited by betulin. Our results suggested that betulin had the potential for the treatment of bone disease, and might be used as a new structural scaffold for osteoclast differentiation inhibitors.

\section{Conclusions}

Betulin inhibited osteoclastogenesis by blocking the expression of NFATc1. Reduced NFATc1 subsequently affected osteoclast differentiation by decreasing osteoclast-related factors, such as DC-STAMP, cathepsin K, and TRAP. Regarding the clinical aspect, betulin might be beneficial in the treatment of bone diseases, such as osteoporosis and rheumatoid arthritis.

Author Contributions: K.-J.K., M.L., and Y.-J.S. conceived and designed the experiments; K.-J.K., Y.L., and H.-G.H. performed the experiments; K.-J.K. and S.H.S. analyzed the data.

Funding: This research received no external funding

Acknowledgments: This study was supported by grants from the National Research Foundation of Korea (NRF) (2016R1A6A3A11930990) and from the Forest Science and Technology Projects (2017024A00-1720-BA01) provided by the Korea Forest Service.

Conflicts of Interest: The authors declare no conflict of interest. The founding sponsors had no role in the design of the study; in the collection, analyses, or interpretation of data; in the writing of the manuscript, or in the decision to publish the results.

\section{References}

1. Rodan, G.A.; Martin, T.J. Therapeutic approaches to bone diseases. Science 2000, 289, 1508-1514. [CrossRef] [PubMed]

2. Teitelbaum, S.L. Bone resorption by osteoclasts. Science 2000, 289, 1504-1508. [CrossRef] [PubMed] 
3. Suda, T.; Takahashi, N.; Udagawa, N.; Jimi, E.; Gillespie, M.T.; Martin, T.J. Modulation of osteoclast differentiation and function by the new members of the tumor necrosis factor receptor and ligand families. Endocr. Rev. 1999, 20, 345-357. [CrossRef] [PubMed]

4. Walsh, M.C.; Kim, N.; Kadono, Y.; Rho, J.; Lee, S.Y.; Lorenzo, J.; Choi, Y. Osteoimmunology: Interplay between the immune system and bone metabolism. Annu. Rev. Immunol. 2006, 24, 33-63. [CrossRef] [PubMed]

5. Teitelbaum, S.L.; Ross, F.P. Genetic regulation of osteoclast development and function. Nat. Rev. Genet. 2003, 4, 638-649. [CrossRef] [PubMed]

6. Boyle, W.J.; Simonet, W.S.; Lacey, D.L. Osteoclast differentiation and activation. Nature 2003, 423, $337-342$. [CrossRef] [PubMed]

7. Takayanagi, H. Mechanistic insight into osteoclast differentiation in osteoimmunology. J. Mol. Med. 2005, 83, 170-179. [CrossRef] [PubMed]

8. Asagiri, M.; Takayanagi, H. The molecular understanding of osteoclast differentiation. Bone 2007, 40, 251-264. [CrossRef] [PubMed]

9. Theill, L.E.; Boyle, W.J.; Penninger, J.M. RANK-L and RANK: T cells, bone loss, and mammalian evolution. Annu. Rev. Immunol. 2002, 20, 795-823. [CrossRef] [PubMed]

10. Yavropoulou, M.P.; Yovos, J.G. Osteoclastogenesis-Current knowledge and future perspectives. J. Musculoskelet. Neuronal Interact. 2008, 8, 204-216. [PubMed]

11. Mensah, K.A.; Ritchlin, C.T.; Schwarz, E.M. RANKL induces heterogeneous DC-STAMP(lo) and DC-STAMP(hi) osteoclast precursors of which the DC-STAMP(lo) precursors are the master fusogens. J. Cell. Physiol. 2010, 223, 76-83. [PubMed]

12. Takayanagi, H.; Kim, S.; Koga, T.; Nishina, H.; Isshiki, M.; Yoshida, H.; Saiura, A.; Isobe, M.; Yokochi, T.; Inoue, J.; et al. Induction and activation of the transcription factor NFATc1 (NFAT2) integrate RANKL signaling in terminal differentiation of osteoclasts. Dev. Cell 2002, 3, 889-901. [CrossRef]

13. Takayanagi, H. Osteoimmunology: Shared mechanisms and crosstalk between the immune and bone systems. Nat. Rev. Immunol. 2007, 7, 292-304. [CrossRef] [PubMed]

14. Kim, K.; Kim, J.H.; Lee, J.; Jin, H.M.; Lee, S.H.; Fisher, D.E.; Kook, H.; Kim, K.K.; Choi, Y.; Kim, N. Nuclear factor of activated $\mathrm{T}$ cells $\mathrm{c} 1$ induces osteoclast-associated receptor gene expression during tumor necrosis factor-related activation-induced cytokine-mediated osteoclastogenesis. J. Biol. Chem. 2005, 280, 35209-35216. [CrossRef] [PubMed]

15. Demain, A.L. Microbial natural products: Alive and well in 1998. Nat. Biotechnol. 1998, 16, 3-4. [CrossRef] [PubMed]

16. Yang, M.; Sun, J.; Lu, Z.; Chen, G.; Guan, S.; Liu, X.; Jiang, B.; Ye, M.; Guo, D.A. Phytochemical analysis of traditional Chinese medicine using liquid chromatography coupled with mass spectrometry. J. Chromatogr. A 2009, 1216, 2045-2062. [CrossRef] [PubMed]

17. Morabito, N.; Crisafulli, A.; Vergara, C.; Gaudio, A.; Lasco, A.; Frisina, N.; D’Anna, R.; Corrado, F.; Pizzoleo, M.A.; Cincotta, M.; et al. Effects of genistein and hormone-replacement therapy on bone loss in early postmenopausal women: A randomized double-blind placebo-controlled study. J. Bone Miner. Res. 2002, 17, 1904-1912. [CrossRef] [PubMed]

18. Rassi, C.M.; Lieberherr, M.; Chaumaz, G.; Pointillart, A.; Cournot, G. Down-regulation of osteoclast differentiation by daidzein via caspase 3. J. Bone Miner. Res. 2002, 17, 630-638. [CrossRef] [PubMed]

19. Jager, S.; Trojan, H.; Kopp, T.; Laszczyk, M.N.; Scheffler, A. Pentacyclic triterpene distribution in various plants-Rich sources for a new group of multi-potent plant extracts. Molecules 2009, 14, 2016-2031. [CrossRef] [PubMed]

20. Yogeeswari, P.; Sriram, D. Betulinic acid and its derivatives: A review on their biological properties. Curr. Med. Chem. 2005, 12, 657-666. [CrossRef] [PubMed]

21. Alakurtti, S.; Makela, T.; Koskimies, S.; Yli-Kauhaluoma, J. Pharmacological properties of the ubiquitous natural product betulin. Eur. J. Pharm. Sci. 2006, 29, 1-13. [CrossRef] [PubMed]

22. Park, S.Y.; Kim, H.J.; Kim, K.R.; Lee, S.K.; Lee, C.K.; Park, K.K.; Chung, W.Y. Betulinic acid, a bioactive pentacyclic triterpenoid, inhibits skeletal-related events induced by breast cancer bone metastases and treatment. Toxicol. Appl. Pharmacol. 2014, 275, 152-162. [CrossRef] [PubMed] 
23. Xu, J.; Li, Z.; Luo, J.; Yang, F.; Liu, T.; Liu, M.; Qiu, W.W.; Tang, J. Synthesis and biological evaluation of heterocyclic ring-fused betulinic acid derivatives as novel inhibitors of osteoclast differentiation and bone resorption. J. Med. Chem. 2012, 55, 3122-3134. [CrossRef] [PubMed]

24. Kim, H.; Kim, K.J.; Yeon, J.T.; Kim, S.H.; Won, D.H.; Choi, H.; Nam, S.J.; Son, Y.J.; Kang, H. Placotylene A, an inhibitor of the receptor activator of nuclear factor-kappaB ligand-induced osteoclast differentiation, from a Korean sponge Placospongia sp. Mar. Drugs 2014, 12, 2054-2065. [CrossRef] [PubMed]

25. Rozen, S.; Skaletsky, H. Primer3 on the WWW for general users and for biologist programmers. Methods Mol. Biol. 2000, 132, 365-386. [PubMed]

26. Livak, K.J.; Schmittgen, T.D. Analysis of relative gene expression data using real-time quantitative PCR and the 2(-Delta Delta C(T)) Method. Methods 2001, 25, 402-408. [CrossRef] [PubMed]

27. Kim, K.J.; Yeon, J.T.; Choi, S.W.; Moon, S.H.; Ryu, B.J.; Yu, R.; Park, S.J.; Kim, S.H.; Son, Y.J. Decursin inhibits osteoclastogenesis by downregulating NFATc1 and blocking fusion of pre-osteoclasts. Bone 2015, 81, $208-216$. [CrossRef] [PubMed]

28. Siddiqui, S.; Hafeez, F.; Begum, S.; Siddiqui, B.S. Oleanderol, a new pentacyclic triterpene from the leaves of Nerium oleander. J. Nat. Prod. 1988, 51, 229-233. [CrossRef]

29. Szuster-Ciesielska, A.; Plewka, K.; Daniluk, J.; Kandefer-Szerszen, M. Betulin and betulinic acid attenuate ethanol-induced liver stellate cell activation by inhibiting reactive oxygen species (ROS), cytokine (TNF-alpha, TGF-beta) production and by influencing intracellular signaling. Toxicology 2011, 280, 152-163. [CrossRef] [PubMed]

30. Genet, C.; Strehle, A.; Schmidt, C.; Boudjelal, G.; Lobstein, A.; Schoonjans, K.; Souchet, M.; Auwerx, J.; Saladin, R.; Wagner, A. Structure-activity relationship study of betulinic acid, a novel and selective TGR5 agonist, and its synthetic derivatives: Potential impact in diabetes. J. Med. Chem. 2010, 53, 178-190. [CrossRef] [PubMed]

31. Raisz, L.G. Pathogenesis of osteoporosis: Concepts, conflicts, and prospects. J. Clin. Investig. 2005, 115, 3318-3325. [CrossRef] [PubMed]

32. Ueda, N.; Koide, M.; Ohguchi, M.; Ishihara, Y.; Noguchi, T.; Okahashi, N.; Nishihara, T. Involvement of prostaglandin E2 and interleukin-1 alpha in the differentiation and survival of osteoclasts induced by lipopolysaccharide from Actinobacillus actinomycetemcomitans Y4. J. Periodontal. Res. 1998, 33, 509-516. [CrossRef] [PubMed]

33. Matsuo, K.; Galson, D.L.; Zhao, C.; Peng, L.; Laplace, C.; Wang, K.Z.; Bachler, M.A.; Amano, H.; Aburatani, H.; Ishikawa, H.; et al. Nuclear factor of activated T-cells (NFAT) rescues osteoclastogenesis in precursors lacking c-Fos. J. Biol. Chem. 2004, 279, 26475-26480. [CrossRef] [PubMed] 